\title{
Entrevista
}

\section{Los algoritmos en esta era digital}

DOI: 10.29236/sistemas.n161a3

Su impacto en la economía, la política y otros aspectos que rodean al ser humano, analizado por Alejandro Sánchez.

\section{Sara Gallardo M.}

Los diecisiete años de experiencia de Alejandro Sánchez en cargos de gerencia y liderazgo en proyectos de construcción de software, soluciones de datos, arquitectura de $\mathrm{TI}$ y transformación digital en el sector público y privado, sumados a la docencia y su doctorado en curso en la Universidad Nacional, los aplica hoy en el área de Machine Learning Delivery de Mercado Libre.

"En mi día a día cuido mis datos evitando, por ejemplo, suministrarlos en páginas en las que puedan ser usados por algoritmos cuyo objetivo sea el spam o el fraude. Los algoritmos, las máquinas y los robots bien aplicados contribuyen a la calidad de vida y a una realidad mixta entre las personas y la inteligencia artificial", asegura el entrevistado.
"Haber sido arquitecto de aplicación en la primera app digital para solicitud de crédito de vivienda https://viviendadigital.bancodebog ota.co/ es algo que me llena de satisfacción, porque sin duda contribuye a cumplir el sueño de vivienda propia de muchas personas. Esta aplicación que diseñé y construí con mi equipo, tuvo reconocimiento en la revista 'The Banker', por la posibilidad de llevar a cabo una solicitud del producto desde cualquier dispositivo móvil, sin necesidad de presentar documentación física”".

Sánchez tiene muy claro estar viviendo en una era digital con mu-

https://www.larepublica.co/finanzas/banco-de-bogotafue-reconocido-por-the-banker-como-el-mejor-bancode-2019-2960794 


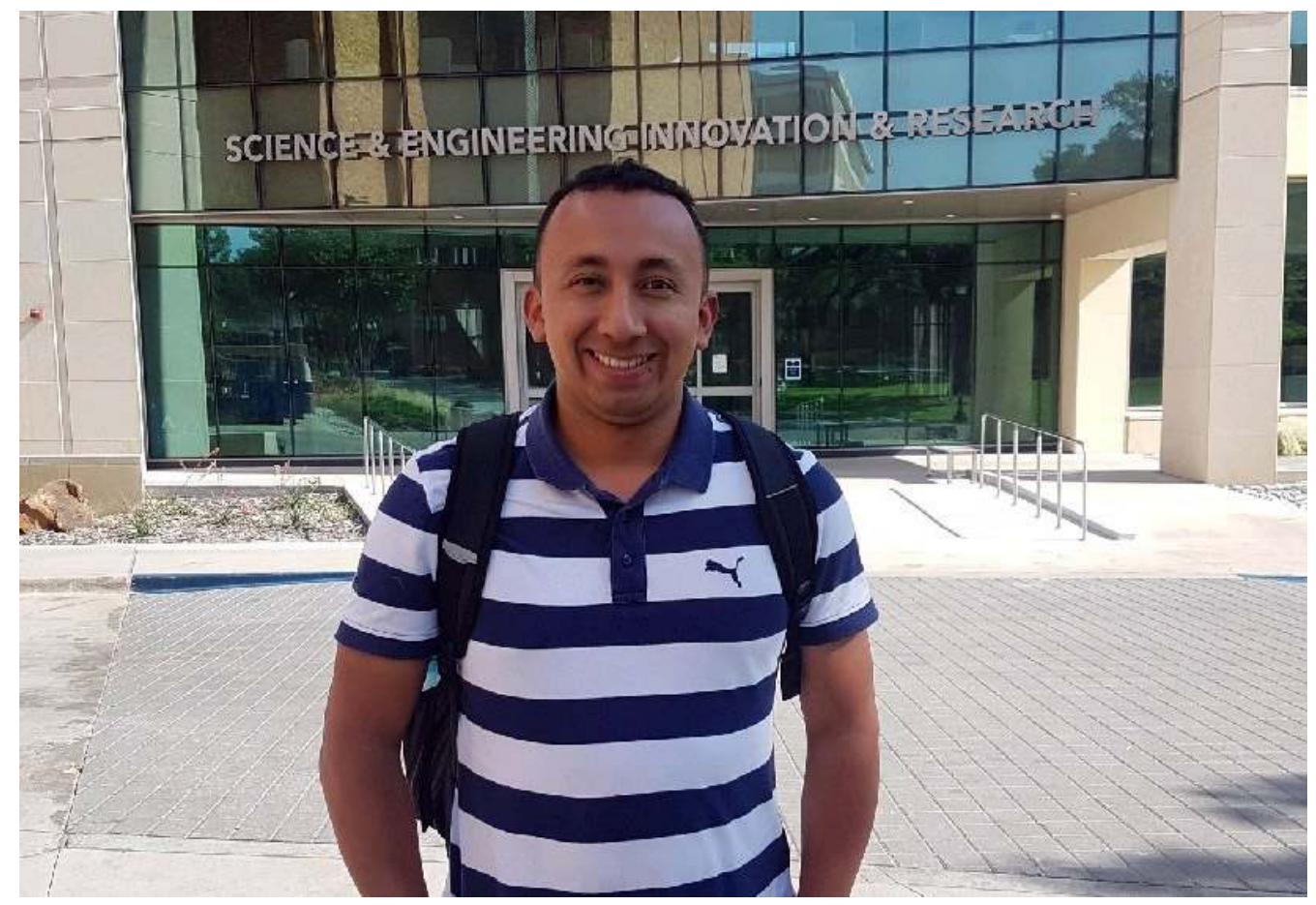

chos beneficios para la humanidad y el planeta, pero también con los riesgos de la deshumanización por no darle la relevancia necesaria a las emociones, la empatía y la comunicación asertiva. Aspectos que, según él, deben considerarse en los algoritmos, los datos y, en general, en la inteligencia artificial.

\section{Revista Sistemas: Las circunstan-} cias actuales han generado en la sociedad múltiples cambios y exigencias. Desde esa perspectiva ¿cómo define el poder de los algoritmos?

Poder es tener la capacidad para hacer algo y algoritmo se refiere a un conjunto finito de acciones o instrucciones que permiten obtener un resultado o resolver un problema a partir de una entrada. Consideran- do las definiciones anteriores, el poder de los algoritmos está en la posibilidad de repetir un conjunto finito de acciones para resolver un problema recurrente o automatizar tareas repetitivas, que de forma manual nos llevarían horas o incluso años a los humanos, quienes podríamos tener también mayor probabilidad de equivocación o fallo.

En las circunstancias actuales, no sólo disponemos de una enorme cantidad de datos, sino que los compartimos a través de búsquedas en Internet, las redes sociales o la adquisición de productos y servicios desde la comodidad del hogar u oficina. Es por eso que ya no sólo está automatizado el proceso de compra en línea de un producto, 
sino los algoritmos que son capaces de hacernos recomendaciones enfocadas en nuestras preferencias y comportamientos de adquisición.

\section{RS: En su opinión ¿cuál es el im- pacto más significativo de los algo- ritmos en la economía del país?}

La automatización para reducción de costos. Si bien la automatización no es un concepto nuevo, el auge y la oportunidad por capacidad de procesamiento que tenemos con la computación en la nube ${ }^{2}$ y la inteligencia artificial, facilita automatizar rápidamente ciertas tareas, habilitar y optimizar servicios, así como generar, usar y disponer datos para tomar mejores decisiones en tiempo real, aplicando algoritmos para análisis descriptivo, predictivo y prescriptivo.

La reducción de costos se puede ver en varios niveles; por una parte, desde la satisfacción del cliente a partir de una excelencia operacional que con datos en tiempo real proporciona un soporte efectivo y oportuno, durante y después de la

Según informe de Accenture, referenciado en la Revista Forbes, Colombia es uno de los países

latinoamericanos con menos porcentaje de negocios en la nube.

https://tienda.digital/la-inteligencia-artificial-debil-ia-debilque-es-y-por-que-existe/

https://telos.fundaciontelefonica.com/inteligenciageneral-artificial-infografia/

Artificial Intelligence, Neil Wilkins

Prediction Machines, The Simple Economics of Artificial Intelligence, Harvard Business Review Press adquisición de un producto o servicio; en segunda instancia desde el valor de la fabricación del producto, porque la automatización disminuye su costo y tiempo de producción; y por último, desde el costo de adopción y adaptación de los algoritmos porque cada vez más organizaciones y personas los usan.

\section{RS: ¿Cómo afectan los espacios de trabajo? ¿Dan lugar al incre- mento de empleo?}

Las tareas repetitivas, manuales o rutinarias son la principal razón por la que se diseñan e implementan algoritmos que las automatizan mediante la ejecución de una serie de instrucciones que no implican pensar, pese a que los algoritmos exhiben cierto nivel de inteligencia al tomar decisiones basadas en los datos de entrada y resolver problemas complejos estos hacen parte de la inteligencia artificial débil o estrecha ${ }^{3}$.

Si queremos que el computador piense como nosotros, tendríamos que hablar de la inteligencia artificial general ${ }^{4}$, a la cual no hemos llegado aún. Cuando se habla de Machine Learning, ésta hace referencia a un nivel de inteligencia artificial estrecha en la que los algoritmos aprenden de los datos de entrada $^{5}$ e incluso se ve a la inteligencia artificial como una tecnología de predicción ${ }^{6}$ que genera datos útiles para la toma de decisiones.

Por lo anterior, debemos adaptarnos y enfocarnos en el tipo de ta- 
reas que no pueden realizarse por medio de un algoritmo y que posiblemente generarán más empleo y serán más requeridas en los espacios de trabajo; por ejemplo: empatía, liderazgo, intuición, creatividad y juicio. Según McKinsey, a finales de 2029 podría automatizarse el $20 \%$ de las actividades comerciales con la tecnología actual y, a mediados de la década de 2030, esta cifra podría llegar a un 30\%. Según Deloitte, hay actividades con alta probabilidad de automatización (mayor al $90 \%$ ) relacionadas con empleos como operadores telefónicos, secretarias y asesores financieros. Estas cifras llevan a pensar que los espacios de trabajo estarían orientados más a la fuerza de trabajo calificada y que posiblemente la no calificada sea más impactada por el desempleo.

\section{RS: En términos sociales ¿cuál es el impacto?}

Sin lugar a duda, la capacidad que dan los algoritmos para aplicar de manera automática una serie de instrucciones y notificar un "me gusta" a una fotografía o un comentario publicado, hoy genera más impacto que si te lo dijeran personalmente, lo cual no es positivo para la interacción social con la que muchos pasamos la niñez y adolescencia. Mejorar aspectos de movilidad a través de algoritmos que consideren variables de congestión en tiempo real, por ejemplo, contribuye no sólo a saber cómo llegar, sino cuánto nos vamos a tardar.
Generalmente nos dicen que cuidemos nuestros datos y evitemos compartirlos con otras personas, pero el impacto también está en el alcance de los algoritmos y cómo usan éstos nuestros datos. Hoy son comunes noticias relacionadas con que redes como Facebook pueden ser empleadas para crear divisiones y expandir el odio ${ }^{7}$, o que parte de sus datos fueron usados para manipular procesos electorales.

\section{RS: Los beneficios que puedan producir los algoritmos ¿llegarán a todos los ciudadanos o solamente a la élite?}

Sin duda los algoritmos pueden llevar beneficios a todos los ciudadanos. Si bien los computadores dominan muchos aspectos en nuestras vidas como las comunicaciones, los sistemas financieros, la atención médica y el control de tráfico aéreo, entre otros, tras bambalinas están los algoritmos aplicados a los datos de entrada, cuyas salidas son claves para la toma de decisiones.

Aún tenemos muchas oportunidades de beneficiarnos con la aplicación de algoritmos en diversas actividades; por ejemplo, la agricultura, no solo para tecnificar sus procesos, sino para facilitar la cadena de producción y distribución de productos, lo cual permitiría no sólo mayores ingresos a los agricultores, sino contribuiría a disminuir la

https://www.bbc.com/mundo/noticias-59133089 
brecha de hambre y la seguridad alimentaria. Según la $\mathrm{FAO}$, entre 720 y 811 millones de personas enfrentaron hambre en 2020 en el mundo ${ }^{8}$.

\section{RS: ¿Cómo afectan las relaciones} interpersonales? ¿Llegará el momento en que el mejor amigo sea un algoritmo?

El mundo digital no sólo diversificó la manera en la que interactuamos con los demás, ahora resulta normal escuchar que una pareja se conoció por Internet e iniciaron una relación, proceso en el que sin duda los algoritmos fueron claves para detectar cosas en común y acercarlos. Pero aún hay muchos desafíos, como el de lograr una conexión más humana y enfocada a la relevancia de las relaciones interpersonales; por ejemplo, en abril de este año Facebook anunció cambios en su algoritmo para dar más visibilidad a publicaciones de amigos cercanos en lugar de las páginas de fans.

No necesariamente un algoritmo será nuestro mejor amigo, pues un amigo es capaz de estar contigo en muchas situaciones, apoyándote y recurriendo a cosas tan humanas como la empatía. El algoritmo puede ser el mejor aliado en una situación o problema particular: determinar la ruta más rápida para llegar al hospital, identificar clientes potenciales, automatizar una tarea que llevaría meses hacerla, encontrar nuevos planetas ${ }^{9}$, etc. Estoy de acuerdo con Stephen Covey sobre el hecho de que "la tecnología reinventará los negocios, pero las relaciones humanas seguirán siendo la clave del éxito".

\section{RS: ¿El alcance de los robots po-} dría dar lugar a la obsolescencia humana? Si los robots todo lo hacen ¿qué queda para el individuo?

No hay lugar para la obsolescencia humana. En la actualidad, los robots reemplazan algunas tareas repetitivas y rutinarias, las cuales se complementan con las tareas humanas orientadas al juicio y la supervisión. La combinación de ambos tipos de tareas ofrece ventajas complementarias. Por ejemplo, dado que un robot aún no es capaz de llevar un paquete, lo siguen haciendo los humanos, pero se usan robots en el proceso de empaque y algoritmos para optimizar la ruta en el proceso de entrega del producto.

Con el auge de la inteligencia artificial, el uso e implementación de algoritmos la predicción y automatización permitirán agilizar procesos y servicios, dejando en los humanos tareas que requieren habilidades con las que no cuentan las máquinas y los robots tales como la empatía, liderazgo, intuición, creatividad y juicio. Hoy contamos no solo con las capacidades humanas, sino la inteligencia y posibilidades de los robots o máquinas. En

\footnotetext{
https://www.fao.org/hunger/es/

https://olhardigital.com.br/es/2020/08/25/seguranca/ algoritmo-encontra-50-novos-exoplanetas-em-bancode-dados-da-nasa-e/
} 
lugar de reemplazarse unos a otros, se complementan y cooperan en diversos escenarios de nuestras vidas, lo que Sherry Turkle denomina horizonte robótico.

\section{RS: ¿Cuál es el efecto en lo políti- co? ¿Podrían ser un mecanismo} para controlar la corrupción o las malas decisiones del Estado? De ser así, ¿ ¿por qué y cómo?

Sin lugar a dudas. En este punto es importante contar con los datos. Por ejemplo, para el caso de contratación, según Open Contracting Partnership ${ }^{10}$, Latinoamérica es un gran lugar para empezar, se cuenta con datos disponibles en portales abiertos que podrían ayudar a identificar períodos cortos de licitación, bajo número de ponentes, etc. (conocidos como banderas rojas o red flags en Inglés).

Con algoritmos que usan los datos disponibles como entrada, podríamos contar con mecanismos para detectar (no sólo históricamente sino en tiempo real), casos de corrupción y análisis de las decisiones del Estado. En este caso, los algoritmos permitirían diversos análisis que, complementados con el juicio y el análisis humano, agilizarán la detección temprana de casos y de posibles acciones.

Aquí juega un papel importante la calidad de datos porque de ellos dependerá la salida o resultados del algoritmo. Podrían aplicarse algoritmos de procesamiento de lenguaje natural para detectar pa- trones de comportamiento y posibles alertas, incluso recomendaciones con inteligencia artificial.

\section{RS: En términos psicológicos ¿cuál es el impacto en el ser hu- mano? ¿Cambiarán el sentido de la vida?}

Hoy nuestras emociones están influenciadas por las diversas redes sociales que usamos y las páginas web que visitamos. El número de likes para muchas personas puede definir su estado de ánimo. Los seres humanos somos emocionales por naturaleza y aunque cosas como los likes o las notificaciones que nos llegan nos afectan en menor o mayor medida a cada uno, finalmente terminamos dependiendo de cómo opera el algoritmo para notificar lo que publicamos tanto a nuestros contactos cercanos como lejanos.

Por otra parte, con los algoritmos es posible predecir el estado de ánimo y en sí la identificación de emociones a partir de lo que escribimos. Lo anterior hace referencia al análisis de sentimientos en los que se aplican algoritmos relacionados con lingüística computacional, procesamiento de lenguaje natural y análisis de texto. El cambio en el sentido de la vida lo vivimos a diario al recibir una notificación que cambia nuestra percepción de un amigo, un político o una empresa.

\footnotetext{
https://www.open-contracting.org/2019/06/27/examiningprocurement-red-flags-in-latin-america-with-data
} 
La incapacidad para detectar casos de bullying en los algoritmos usados en las redes sociales podría cambiarle el sentido de la vida a una persona porque incluso se ha llegado a casos extremos como el suicidio.

\section{RS: Y con relación a la ética ¿basta con legislar al respecto?, o ¿se re- quiere algo más para lograr su uso responsable?}

No sólo se requiere legislación para su uso responsable, sino conocimiento de marcos éticos y compromiso de todos los actores que intervienen para su buen funcionamiento. Como usuario digital debo ser consciente de los riesgos que me traen comportamientos tales como hacer clic en un enlace que no conozco o usar una contraseña poco segura, acciones que pueden desencadenar la ejecución de algoritmos malintencionados que podrían robar nuestros datos e información para usarlos en forma fraudulenta.

La legislación nos da un marco de referencia para acelerar la operación con ética. Contar con marcos éticos disminuye la brecha entre la aplicación y la regulación, pero se requiere un compromiso de las empresas y la supervisión de los gobiernos para que se ejecuten acciones orientadas al monitoreo del cumplimiento de la legislación, además de la aplicación sin excep-

https://inteligenciaartificial.gov.co/marco-eticos/ ción de sanciones cuando haya lugar. Lo anterior se requiere no solo a nivel de algoritmos, sino de datos e inteligencia artificial.

\section{RS: ¿Cuál es la responsabilidad é- tica de las empresas?}

Incluir como parte de su arquitectura de negocio y de TI el cumplimiento de los marcos de ética, así como métricas y lineamientos que permitan monitorear y evaluar su nivel de cumplimiento en cualquier proyecto de software o datos en la empresa donde precisamente los algoritmos serán parte de la documentación y codificación. También es su responsabilidad el uso adecuado de los datos o información de entrada y salida de los algoritmos a nivel de ciberseguridad, seguridad informática y seguridad de la información.

Promover, exigir y medir valores éticos a cada uno de sus directivos y empleados es crucial, así como considerarlos dentro de sus principios y cultura. La ética debe ser considerada desde la fase de concepción o descubrimiento de cada proyecto a nivel de datos, algoritmos y prácticas, independientemente del paradigma tecnológico bajo el que se vaya a abordar. Por fortuna, la dinámica digital ha hecho que de manera temprana contemos con marcos éticos y recomendaciones (por ejemplo: Marco Ético sobre para la Inteligencia Artificial en Colombia ${ }^{11}$ y Recomendaciones sobre la Ética de la Inteligencia Artificial de la UNESCO). 
RS: Los algoritmos se soportan en datos a menudo sensibles y obtenidos obligando a las personas a autorizar su uso para recibir un servicio. ¿Esto es ético?

No es ético cuando la única opción es aceptar los términos y condiciones impuestos para recibir un servicio permitir la posibilidad de decidir cuáles datos o qué información pueden usar y cuál no. La autorización de uso de los datos generalmente carece de una buena experiencia de usuario porque son letra menuda que no es fácil de comprender.

Como usuario digital siempre recuerdo una frase dada en el documental The Social Dilemma de Netflix: "Si no pagas por el producto, entonces tú eres el producto".

La pandemia nos demostró la importancia de ser digitales y de los procesos de transformación digital, por lo que muchas empresas empezaron a ofrecer sus productos y servicios rápidamente; ahora es tiempo de actuar sobre el uso de los datos capturados y gestionados porque, así como pueden ser usados para los fines inicialmente contemplados, pueden ser usados para otros fines tanto en las empresas que los usan y custodian, como por terceros.

\section{RS: En la medida en que la perso- na aceptó los términos de uso ¿quién es el responsable si algo sa- le mal?, ¿la empresa, el desarro- llador, otro?}

Todos tienen responsabilidad, pero en mayor grado la tiene la empresa y el desarrollador porque el uso adecuado de los datos y salidas del algoritmo debieron contemplarse durante toda la fase de construcción de un producto y su operación. Desde el momento que confío mis datos a una empresa o software, es responsabilidad de ella su uso adecuado porque se convierten en custodios de la misma.

Sin duda es una responsabilidad compleja para la empresa, desde las implicaciones de ciberseguridad, código seguro y uso adecuado de los datos, pero la debe asumir con sus equipos de desarrollo. Si bien es imposible contemplar todos los escenarios de fracaso en las pruebas de software antes de Ilevarlo a producción, hoy se cuenta con marcos de trabajo orientados a una excelencia operacional que, a través de tácticas como el monitoreo y las alertas, pueden encontrar eventos o incidentes no deseados tempranamente.

\section{RS: A sabiendas de que los algorit-} mos no son infalibles y siempre hay un margen de error ¿podemos darles responsabilidades de vida o muerte?

Las tienen desde hace mucho tiempo y fueron cruciales para grandes logros de la humanidad, llevar al hombre a la luna, por ejemplo. Hoy los algoritmos de machine learning contribuyen para que los investigadores puedan comprender virus como el COVID-19, encontrar las zo- 
nas con más altas tasas de contagio, predecir la capacidad requerida de Unidades de Cuidado Intensivo (UCl) y a mayor escala de los sistemas de salud, con el fin de disminuir el número de muertes. Los algoritmos también ayudan a identificar patrones del virus en las primeras etapas y de esa manera, predecir casos que pueden agravarse en el futuro.

Si bien hay casos en los que los algoritmos no tienen los resultados esperados como el que se menciona en el artículo "El fracaso mundial de las IA para atrapar al coronavirus", esto corresponde más a la calidad de los datos de entrada que produce resultados erróneos (lo que se conoce popularmente en inglés como garbage in, garbage out, si la calidad de los datos de entrada no es buena, el resultado de los datos de salida tampoco lo será). Los algoritmos son usados para diagnosticar enfermedades como el cáncer, a partir no sólo de datos estructurados, sino no estructurados como las imágenes. Hoy hay campos como el computer visión, cruciales para comprender muchos asuntos de vida o muerte de forma confiable aprovechando el auge del IoT (Internet de las Cosas por sus siglas en inglés) y más allá de su aplicación en vehículos autónomos. 程

Sara Gallardo M. Periodista comunicadora, universidad Jorge Tadeo Lozano. Ha sido directora de las revistas Uno y Cero, Gestión empresarial y Acuc Noticias. Editora de Aló Computadores del diario El Tiempo. Redactora en las revistas Cambio 16, Cambio y Clase Empresarial. Coautora del libro "Lo que cuesta el abuso del poder". Ha sido corresponsal de la revista Infochannel de México; de los diarios La Prensa de Panamá y La Prensa Gráfica de El Salvador y corresponsal de la revista IN de Lanchile e investigadora en publicaciones culturales. Se ha desempeñado también como gerente de Comunicaciones y Servicio al Comensal en Inmaculada Guadalupe y amigos en Cía. S.A. (Andrés Carne de Res) y editora de Alfaomega Colombiana S.A.; asesora en escritura y producción de libros; es editora de esta revista. 